BMC

Pediatrics

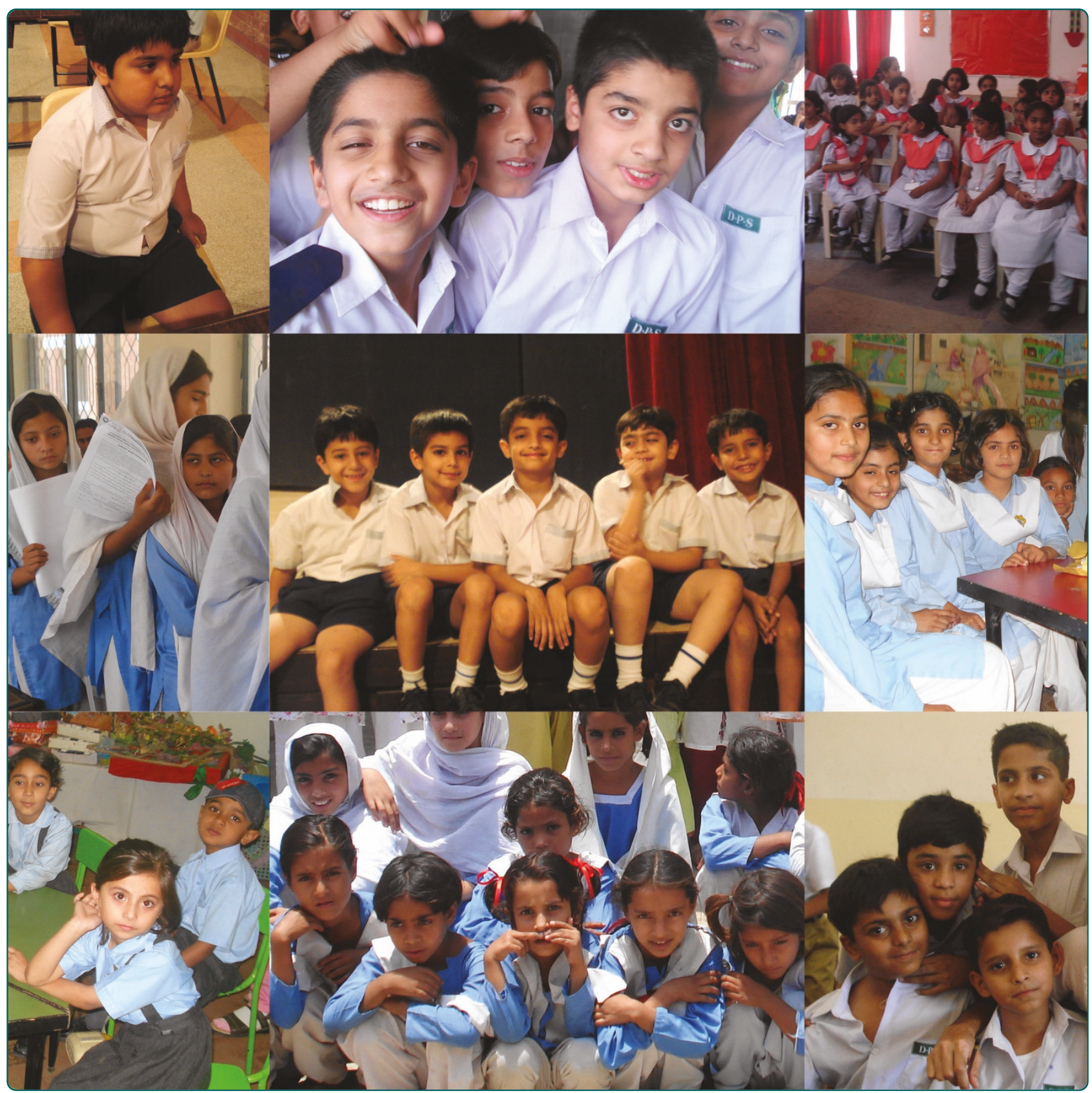

Family-based factors associated with overweight and obesity among Pakistani primary school children

Mushtaq et al. 


\title{
Family-based factors associated with overweight and obesity among Pakistani primary school children
}

\author{
Muhammad Umair Mushtaq ${ }^{1,2^{*}}$, Sibgha Gull ${ }^{1}$, Ubeera Shahid ${ }^{1}$, Mahar Muhammad Shafique ${ }^{1}$ \\ Hussain Muhammad Abdullah', Mushtaq Ahmad Shad ${ }^{2}$ and Arif Mahmood Siddiqui ${ }^{1}$
}

\begin{abstract}
Background: Childhood obesity epidemic is now penetrating the developing countries including Pakistan, especially in the affluent urban population. There is no data on association of family-based factors with overweight and obesity among school-aged children in Pakistan. The study aimed to explore the family-based factors associated with overweight and obesity among Pakistani primary school children.

Methods: A population-based cross-sectional study was conducted with a representative multistage cluster sample of 1860 children aged five to twelve years in Lahore, Pakistan. Overweight (> +1SD BMI-for-age $z$-score) and obesity ( $>+2$ SD BMI-for-age $z$-score) were defined using the World Health Organization reference 2007. Chi-square test was used as the test of trend. Linear regression was used to examine the predictive power of independent variables in relation to BMI. Logistic regression was used to quantify the independent predictors of overweight and adjusted odds ratios (aOR) with 95\% confidence intervals $(\mathrm{Cl})$ were obtained. All regression analyses were controlled for age and gender and statistical significance was considered at $\mathrm{P}<0.05$.

Results: Significant family-based correlates of overweight and obesity included higher parental education $(\mathrm{P}<$ 0.001), both parents working $(P=0.002)$, fewer siblings $(P<0.001)$, fewer persons in child's living room $(P<0.001)$ and residence in high-income neighborhoods $(P<0.001)$. Smoking in living place was not associated with overweight and obesity. Higher parental education $(P<0.001)$ and living in high-income neighborhoods $(P<$ 0.001) showed a significant independent positive association with BMI while greater number of siblings $(P=0.001)$ and persons in child's living room ( $P=0.022)$ showed a significant independent inverse association. College-level or higher parental education as compared to high school-level or lower parental education (aOR 2.54, 95\% Cl 1.763.67), living in high-income neighborhoods as compared to low-income neighborhoods (aOR 2.13, 95\% Cl 1.31-

3.46) and three or less siblings as compared to more than three siblings (aOR 1.75, 95\% Cl 1.26-2.42) were significant independent predictors of overweight.
\end{abstract}

Conclusion: Family-based factors were significantly associated with overweight and obesity among school-aged children in Pakistan. Higher parental education, living in high-income neighborhoods and fewer siblings were independent predictors of overweight. These findings support the need to design evidence-based child health policy and implement targeted interventions, considering the impact of family-based factors and involving communities.

\footnotetext{
* Correspondence: mushtaqmu@gmail.com

'Ubeera Memorial Research Society, Allama Iqbal Medical College, Lahore,

54000 Punjab, Pakistan

Full list of author information is available at the end of the article
} 


\section{Background}

Obesity is a global epidemic and children are the worst affected with an estimated ten percent of school-aged children being overweight and one quarter of these being obese worldwide [1,2]. The 2004 World Health Assembly at Geneva called for specific action to halt the epidemic that is now penetrating the developing countries including Pakistan, especially in the affluent urban population [3-5]. Childhood obesity adversely affects physiological and psychosocial well-being, results in cardiovascular and metabolic diseases, leads to increased mortality and morbidity, and causes heavy health expenditures and reduced social status [1,6-8]. Targeted interventions for the prevention of childhood obesity, tailored to local circumstances and involving communities, should begin early in life [9].

Influence of family environment and parental characteristics has important consequences regarding childhood obesity and it should be considered in designing policies and interventions [10-12]. Globally, the relationship between childhood obesity and family-based factors, including parental education, parental working status, siblings, persons in child's living room, smoking in living space and neighborhood income level has been extensively explored [13-32]. However, most studies are conducted in the developed countries and literature is scarce in this regard among South Asian children. There is no data on association of family-based factors with overweight and obesity among school-aged children in Pakistan. The study aimed to explore family-based factors associated with overweight and obesity among Pakistani primary school children.

\section{Methods}

\section{Design, setting and sample}

A population-based cross-sectional study titled 'Nutritional Assessment among School-going Children in Lahore, Pakistan (NASCL)' was conducted among primary school children aged five to twelve years in 2009-2010. Lahore, a metropolis with multiethnic populations, is the capital of Pakistan's most populous province Punjab. It has a population of nine million including 2.5 million primary school children, and $81 \%$ of the population resides in the urban area (Administrative data, Government of the Punjab, 2010).

A stratified, multistage cluster sample of 1860 children aged five to twelve years in twelve primary schools of City District Lahore was enrolled. The sampling design has been used previously in nutritional assessment surveys [19,28,29,33-35]. Stratified sampling, based on the population and educational system characteristics, was used to have proportionate representation of gender, area of residence and socioeconomic status (SES). The list of all public and private primary schools in Lahore was provided by the Punjab Department of Education. The listed schools were stratified according to the geographic area and monthly fee structure of schools into following four strata: a) urban with high SES (urban area and fee $>2500$ PKR), b) urban with middle SES (urban area and fee $=1000-2500$ PKR), c) urban with low SES (urban area and fee $<1000$ PKR), and d) rural with low/disadvantaged SES (rural area and fee $\sim 100$ PKR or free). The former two strata included private (including public-private mix) schools and the later two strata included public schools. In Pakistan, public schools cater low SES urban and rural children while high SES and middle SES urban children are educated in private and public-private mix schools. Three schools were selected at random from each stratum and contacted by the Departments of Education and Health to participate voluntarily in the study. If the school administration refused to participate, next school was selected randomly from the respective stratum. For each school, a list of all classes in five grades (one to five) was obtained and one class in each grade was selected at random. In this way, sixty classes, five from each school, were selected. For each of the selected classes, first thirty-one children on class attendance register, present on data collection day and aged five to twelve years, were included in the study. Participation of children in the study was voluntary. Children suffering from any known metabolic syndrome (e.g. Prader-Willi syndrome) were excluded. Sample size was calculated using Epi Info 6.04d (United States Centers for Disease Control and Prevention, 2004) with a confidence (1- $\alpha)$ of $95 \%$, anticipated prevalence of $5 \%$ and margin of error of \pm 1 . The minimum sample size calculated was 1823 and a sample of 1860 was deemed sufficient.

\section{Data Collection}

The sampled schools were visited on pre-arranged dates in summer 2009 by a team of trained senior medical students lead by the Principal Investigator. Health education of children and teachers was also carried out after data collection in the respective school. Analogue physician health scales, standardized before the examination, were used [36]. Height in centimeters $(\mathrm{cm})$ and weight in kilograms $(\mathrm{kg})$ were measured following the standard procedure to the nearest $0.1 \mathrm{~cm}$ and $0.5 \mathrm{~kg}$ respectively. The child was asked to stand relax, feet were placed together with heels, buttocks and shoulder blades against the stick and head was positioned in the Frankfurt horizontal plane. All measurements were taken in light summer school uniform without shoes during mornings or early afternoons. Most frequently used measure for obesity is body mass index (BMI), defined as weight $(\mathrm{kg}) /$ height 
squared $\left(\mathrm{m}^{2}\right)$, and BMI-for-age is the anthropometric index of relative weight recommended by the international expert committees [37].

For each of the sampled classes, demographic information of all officially enrolled students was obtained before data collection, including gender, date of birth, residential address and parental education. Demographic information of students not found on official rosters but currently enrolled in that class was obtained from class teachers. Among measures of social class, parental education had been most strongly related to childhood obesity $[14,15]$. Parental education level was based on the parent with the highest total years of schooling and neighborhood income level was based on the approximate income estimate of child's residential area obtained from the Revenue Department of City District Government Lahore.

The study instrument was a structured questionnaire, designed in English. Study instruments and procedures were pre-tested in the field and modified accordingly. The questionnaire included questions regarding familybased factors including parental working status, siblings, persons in child's living room and smoking in living space $[38,39]$. Senior medical students trained in the interviewing techniques interviewed children in presence of their class teacher (guardian). Each child was asked regarding whether his/her mother works outside or is she a housewife, how many older/younger siblings he/ she has and how many persons are living in his/her living room? Smoking was defined as smoking tobacco by cigarette, cigar, pipe or hookah. Hookah (water pipe) is a single or multi-stemmed instrument used for smoking tobacco in South Asia.

Quality control measures and good practices including training, pre-testing the processes and materials, field monitoring of data collection, logistics management and daily meetings of the study teams were ensured. Informed consent statement was printed on the form. Verbal informed consent for the child to participate in the study was taken from class teachers and school heads. As the study involved no invasive procedure, verbal informed consent was deemed sufficient. The study was approved by the Ethical Review Board of Allama Iqbal Medical College, Lahore. Permissions to conduct the study were granted by the Punjab Departments of Education and Health, and the sampled schools.

\section{Statistical Analysis}

Data were entered and analyzed by manual and computerized checking using SPSS version 18.0 (SPSS Inc. Chicago IL, United States, 2009). Age was calculated to the precise day by subtracting the date of birth from the date of examination. The $\mathrm{z}$-score values for BMI-for-age were calculated using the World Health Organization's software,
AnthroPlus, for assessing growth of the world's children and adolescents (WHO, 2009). Overweight ( $>+1$ SD BMIfor-age z-score) and obesity (> +2SD BMI-for-age z-score) were defined using the WHO reference 2007 [40,41].

Bivariate analysis, using chi-square test as the test of trend, was conducted to compare differences in the prevalence of overweight and obesity relative to familybased factors. Crude odds ratios (OR) with $95 \%$ confidence interval $(\mathrm{CI})$ were calculated to examine the relationship between overweight and family-based factors by univariate analyses. Linear regression was used to examine the predictive power of family-based factors (independent variables) in relation to BMI (dependent variable). Multivariate logistic regression was used to estimate the simultaneous effect of several covariates on a dichotomous outcome. Parental education, parental working status, siblings, persons in child's living room and neighborhood income were entered into the multivariate model concurrently to quantify their independent importance for risk of being overweight and adjusted odds ratios (aOR) with 95\% CI were obtained. All regression analyses were controlled for age and gender. Statistical significance was considered at $\mathrm{P}<0.05$ and all tests were two-sided.

\section{Results}

The study included a sample of 1860 primary school children aged five to twelve years. The male-female ratio was 1.11 with $52.5 \%$ boys and $47.5 \%$ girls. The sample involved 20\% children from each grade and $25 \%$ children from each area and SES stratum. Twenty percent parents were illiterate followed by those educated up to high school (27\%), college (28\%) and higher (25\%). Majority of children had one to three siblings (54\%) followed by more than three siblings (44\%) and no sibling (1\%). Most children (51\%) had more than three persons in living room followed by one to three persons (43\%) and no person (6\%). Smoking in living place was $30 \%$. Most children $(49 \%)$ lived in middle-income neighborhoods followed by low-income (35\%) and high-income (16\%) neighborhoods. Median age (range) was $8(5-12)$ years and mean age (SD) was 8.49 (1.81) years. Mean (SD) BMI was 20.7 (5.02) $\mathrm{kg} / \mathrm{m}^{2}$ and mean (SD) BMI-for-age z score was -0.3 (1.5). Fifty-one percent children had normal weight status (-1SD to +1SD BMI-for-age z-score), 9.5\% children were overweight $(>+1 \mathrm{SD}$ to $+2 \mathrm{SD}$ BMI-for-age $\mathrm{z}$-score) and $7.5 \%$ children were obese $(>+2 \mathrm{SD}$ BMI-for-age $\mathrm{z}$ score) while under-nutrition or thinness $(<-1$ SD BMIfor-age z-score) was observed in $32 \%$ children.

Association of family-based factors with overweight and obesity is shown in Table 1. Children whose parents were having college (23\%) or higher $(29 \%)$ education had significantly higher risk of being overweight and obese $(\mathrm{P}<0.001)$ as compared to children whose parents were 
Table 1 Association of family-based factors with overweight and obesity among Pakistani primary school children (n = 1860)

\begin{tabular}{|c|c|c|c|c|c|c|c|}
\hline \multirow[b]{2}{*}{ Family-based factors } & \multirow{2}{*}{$\begin{array}{l}\text { Total } \\
(\mathrm{n}=1860) \\
\mathrm{n}(\%)\end{array}$} & \multirow{2}{*}{$\begin{array}{l}\text { Thin }^{a} \\
(n=601) \\
n(\%)\end{array}$} & \multirow{2}{*}{$\begin{array}{l}\begin{array}{l}\text { Normal }^{b} \\
(n=943)\end{array} \\
n(\%)\end{array}$} & \multirow{2}{*}{$\begin{array}{l}\begin{array}{l}\text { Overweight }^{c} \\
(\mathrm{n}=176)\end{array} \\
\mathrm{n}(\%)\end{array}$} & \multirow{2}{*}{$\begin{array}{l}\begin{array}{l}\text { Obese }^{d} \\
(n=140)\end{array} \\
n(\%)\end{array}$} & \multicolumn{2}{|c|}{ Significance } \\
\hline & & & & & & $\chi^{2}$ & $P$ value \\
\hline \multicolumn{8}{|l|}{ Parental education } \\
\hline Illiterate & $366(19.7)$ & $163(44.5)$ & $193(52.7)$ & $8(2.2)$ & $02(0.5)$ & 161.56 & $<0.001$ \\
\hline High school & $496(26.7)$ & $193(38.9)$ & $255(51.4)$ & $33(6.7)$ & $15(3.0)$ & & \\
\hline College & $531(28.5)$ & $142(26.7)$ & $268(50.5)$ & $66(12.4)$ & $55(10.4)$ & & \\
\hline Higher education & $467(25.1)$ & $103(22.1)$ & $227(48.6)$ & $69(14.8)$ & $68(14.6)$ & & \\
\hline \multicolumn{8}{|l|}{ Parental working status } \\
\hline Father only & $1465(78.8)$ & $496(33.9)$ & $742(50.6)$ & $125(8.5)$ & $102(7.0)$ & 14.32 & 0.002 \\
\hline Both parents & $395(21.2)$ & $105(26.6)$ & $201(50.9)$ & $51(12.9)$ & $38(9.6)$ & & \\
\hline \multicolumn{8}{|l|}{ Siblings } \\
\hline No & $26(1.4)$ & $6(23.1)$ & $11(42.3)$ & $4(15.4)$ & $5(19.2)$ & 98.33 & $<0.001$ \\
\hline $1-3$ & $1008(54.2)$ & $262(26.0)$ & $511(50.7)$ & $121(12.0)$ & $114(11.3)$ & & \\
\hline$>3$ & $826(44.4)$ & $333(40.3)$ & $421(51.0)$ & $51(6.2)$ & $21(2.5)$ & & \\
\hline \multicolumn{8}{|c|}{ Persons in child's living room } \\
\hline No & $116(6.2)$ & $24(20.7)$ & $48(41.4)$ & $28(24.1)$ & $16(13.8)$ & 77.84 & $<0.001$ \\
\hline $1-3$ & $791(42.5)$ & $212(26.8)$ & $420(53.1)$ & $86(10.9)$ & $73(9.2)$ & & \\
\hline$>3$ & $953(51.2)$ & $365(38.3)$ & $475(49.8)$ & $62(6.5)$ & $51(5.4)$ & & \\
\hline \multicolumn{8}{|l|}{ Smoking in living place } \\
\hline Yes & $546(29.4)$ & $194(35.5)$ & $263(48.2)$ & $52(9.5)$ & $37(6.8)$ & 4.04 & 0.731 \\
\hline No & $1314(70.6)$ & $407(31.0)$ & $680(51.8)$ & $124(9.4)$ & $103(7.8)$ & & \\
\hline \multicolumn{8}{|l|}{ Neighborhood income } \\
\hline Low & $651(35.0)$ & $293(45.0)$ & $316(48.5)$ & $28(4.3)$ & $14(2.2)$ & 145.68 & $<0.001$ \\
\hline Middle & $910(48.9)$ & $247(27.1)$ & $486(53.4)$ & $98(10.8)$ & $79(8.7)$ & & \\
\hline High & 299 (16.1) & $61(20.4)$ & $141(47.2)$ & $50(16.7)$ & 47 (15.7) & & \\
\hline
\end{tabular}

a $<-1$ SD BMI-for-age $z$-score relative to the World Health Organization reference 2007

b-1SD to +1SD BMI-for-age z-score relative to the World Health Organization reference 2007

c > +1SD to +2SD BMI-for-age z-score relative to the World Health Organization reference 2007

d > +2SD BMl-for-age z-score relative to the World Health Organization reference 2007

illiterate (3\%) and educated up to high school (10\%). Overweight and obesity were significantly higher among children with parents having higher education among both boys and girls (both $\mathrm{P}<0.001$ ) [Figure 1]. Children whose both parents were working $(22.5 \%)$ were significantly more likely to be overweight and obese $(\mathrm{P}=0.002)$ than those whose mother was a housewife (15.5\%). Overweight and obesity were $9 \%$ among children having more than three siblings that significantly increased to $23 \%$ among children having one to three siblings and $35 \%$ among children having no sibling $(\mathrm{P}<0.001)$. Twelve percent children having more than three persons in living room were overweight and obese that significantly increased to $20 \%$ among children with one to three persons in living room and 38\% among children with no person in living room $(\mathrm{P}<0.001)$. Smoking in living place was not associated with overweight and obesity. Children living in high-income neighborhoods (32\%) were significantly more likely to be overweight and obese $(\mathrm{P}<0.001)$ than those living in middle-income $(19.5 \%)$ and low-income $(6.5 \%)$ neighborhoods. Higher overweight and obesity prevalence in high-income neighborhoods was observed among both boys and girls (both $\mathrm{P}<0.001$ ) [Figure 2].

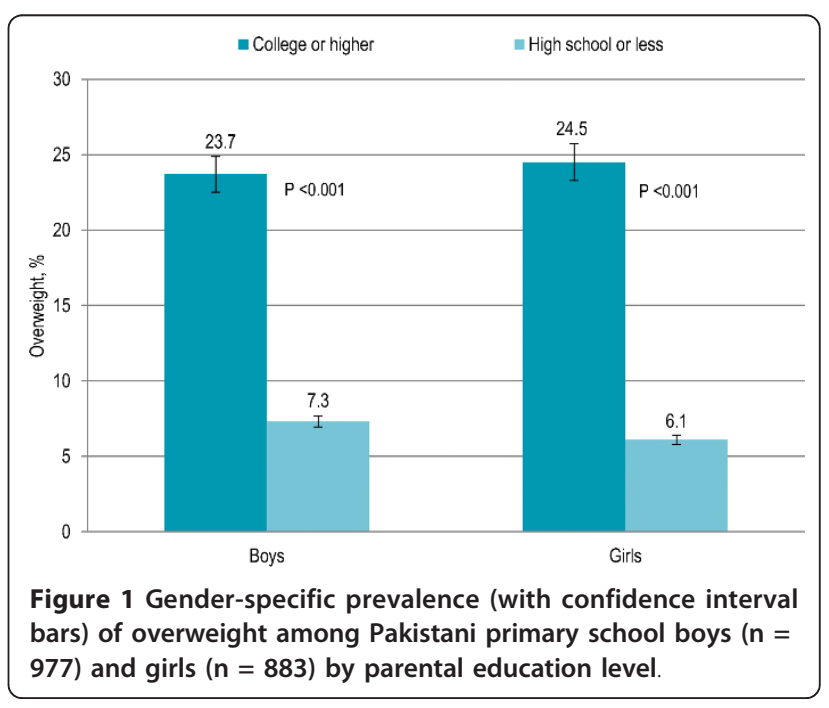




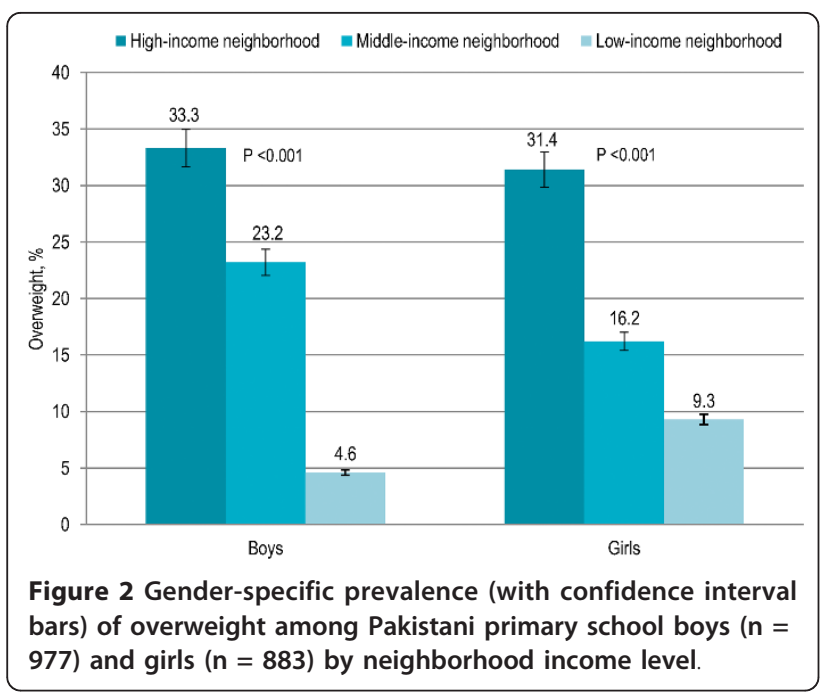

College-level or higher parental education as compared to high school-level or lower parental education (aOR 2.54, 95\% CI 1.76-3.67), living in high-income neighborhoods as compared to low-income neighborhoods (aOR 2.13, 95\% CI 1.31-3.46) and three or less siblings as compared to more than three siblings (aOR 1.75, 95\% CI 1.26-2.42) were significant independent predictors of overweight [Table 2]. Higher parental education $(\mathrm{P}<$ $0.001)$ and living in high-income neighborhoods $(\mathrm{P}<$ 0.001 ) showed a significant independent positive association with $\mathrm{BMI}$ while greater number of siblings $(\mathrm{P}=$ $0.001)$ and persons in child's living room $(P=0.022)$ showed a significant independent inverse association with BMI [Table 3].

\section{Discussion}

This was the first study with a representative sample to explore association of family-based factors with overweight and obesity among Pakistani school-aged children. Higher parental education was significantly associated with overweight and obesity among both boys and girls. Children with parents having college-level or higher education were independently more likely to be overweight as compared to children with parents having high school-level or lower education. Higher parental education was independent predictor of higher BMI. Positive association of childhood obesity with higher parental education had been observed in the developing countries [16,21]; however, studies in the developed countries had shown inverse association of parental education with obesity $[18,19,42]$. Children whose both parents were working had significantly higher rates of overweight and obesity than those whose mother was a housewife; however, in adjusted regression analyses, the effect did not remain significant. Maternal employment had been associated with childhood obesity previously
[20]. Female employment increases family income contributing to improved child health; however, it often adversely affects child nutrition because of the effects on breastfeeding and maternal care-giving [43].

Fewer siblings and less crowded housing are indirect indicators of higher socioeconomic class [38,39]. Fewer siblings and fewer persons in child's living room had significant association with overweight and obesity, and both factors showed a significant independent inverse association with BMI. These findings are consistent with previous studies $[19,21,22]$. Children having three or less siblings were independently more likely to be overweight as compared to children having more than three siblings. Overweight was not significantly associated with persons in child's living room in regression analysis adjusted for all family-based factors. Smoking in living place had been associated with overweight and obesity in previous literature $[17,19,20,22,23]$, but no association was observed in the present study.

Children living in high-income neighborhoods were more likely to be overweight and obese as compared to children living in middle-income and low-income neighborhoods, and the trend was significant among both boys and girls. Higher neighborhood income showed a significant independent association with higher BMI. Children living in high-income neighborhoods were independently more likely to be overweight as compared to children living in low-income neighborhoods. Childhood obesity has been associated with higher socioeconomic class in the developing countries [24-27,42,44]; however, studies in the developed world have shown inverse association of socioeconomic class with childhood obesity [15,28-31,45-47]. Different sociocultural circumstances in the developing countries undergoing nutrition transition explain the contradiction and association between socioeconomic factors and over-nutrition vary in societies at different stages of transition. Obesity is positively associated with socioeconomic factors in Asia but not in Latin America [32]. In South Asia, children from affluent families tend to be heavier than those who are socioeconomically disadvantaged. Changes in lifestyle among children with higher socioeconomic class including unhealthy diets, reduced physical activity and increased sedentary living, reinforced by many of the cultural changes associated with globalization, are the probable underlying causes [48-50]. Children from families having higher socioeconomic class lead a very unhealthy life in this region. They are transported to and from school by car and bus. Sports have been replaced by television, video games and the internet. Parents are busier than ever, household work is done by the servants, families eat fewer home-cooked meals, breakfast skipping is a habit and snacking between meals is the norm. Children from 


\begin{tabular}{|c|c|c|c|c|c|c|c|}
\hline & $\begin{array}{l}\text { Total }^{\mathrm{a}} \\
(\mathrm{n}=1259)\end{array}$ & Normal weight $^{\mathrm{b}}(\mathrm{n}=943)$ & Overweight $^{c}(n=316)$ & $\begin{array}{l}\text { Crude OR } \\
(95 \% \mathrm{Cl})\end{array}$ & $P$ Value & $\begin{array}{l}\text { Adjusted OR } \\
(95 \% \mathrm{Cl})^{\mathrm{d}}\end{array}$ & P Value \\
\hline Family-based factors & n (\%) & n (\%) & n (\%) & & & & \\
\hline \multicolumn{8}{|l|}{ Parental education } \\
\hline High school or less & $506(40.2)$ & $448(88.5)$ & $58(11.5)$ & Reference & - & Reference & - \\
\hline College or higher & $753(59.8)$ & $495(65.7)$ & $258(34.3)$ & $4.03(2.95-5.50)$ & $<0.001$ & $2.54(1.76-3.67)$ & $<0.001$ \\
\hline \multicolumn{8}{|l|}{ Parental working status } \\
\hline Father only & $969(77.0)$ & $742(76.6)$ & $227(23.4)$ & Reference & - & Reference & - \\
\hline Both parents & $290(23.0)$ & $201(69.3)$ & $89(30.7)$ & $1.45(1.08-1.94)$ & 0.013 & $0.85(0.62-1.16)$ & 0.306 \\
\hline \multicolumn{8}{|l|}{ Siblings } \\
\hline$\leq 3$ & $766(60.8)$ & $522(68.1)$ & $244(31.9)$ & $2.73(2.04-3.66)$ & $<0.001$ & $1.75(1.26-2.42)$ & 0.001 \\
\hline$>3$ & $493(39.2)$ & $421(85.4)$ & $72(14.6)$ & Reference & - & Reference & - \\
\hline \multicolumn{8}{|c|}{ Persons in child's living room } \\
\hline$\leq 3$ & $671(53.3)$ & $468(69.7)$ & $203(30.3)$ & $1.82(1.40-2.37)$ & $<0.001$ & $1.11(0.83-1.49)$ & 0.480 \\
\hline$>3$ & $588(46.7)$ & $475(80.8)$ & $113(19.2)$ & Reference & - & Reference & - \\
\hline \multicolumn{8}{|l|}{ Neighborhood income } \\
\hline Low & $358(28.4)$ & $316(88.3)$ & $42(11.7)$ & Reference & - & Reference & - \\
\hline Middle & $663(52.7)$ & $486(73.3)$ & $177(26.7)$ & $2.74(1.90-3.95)$ & $<0.001$ & $1.39(0.91-2.13)$ & 0.129 \\
\hline High & $238(18.9)$ & $141(59.2)$ & $97(40.8)$ & 5.18 (3.43-7.82) & $<0.001$ & $2.13(1.31-3.46)$ & 0.002 \\
\hline
\end{tabular}

aThe model excludes under-nourished children having a BMI-for-age $z$-score of $<-1$ SD relative to the World Health Organization reference 2007 $(n=601)$

-1SD to +1SD BMI-for-age $z$-score relative to the World Health Organization reference 2007

$c>+1$ SD BMI-for-age $z$-score relative to the World Health Organization reference 2007 (includes obese children)

${ }^{\mathrm{d}}$ The model is adjusted for age and gender 
Table 3 Linear regression analysis of family-based factors with BMI among Pakistani primary school children ( $\mathrm{n}=$ $1860)^{\mathrm{a}, \mathrm{b}}$

\begin{tabular}{llll}
\hline Characteristics & Regression coefficient $\mathbf{9 5 \%} \mathbf{C l})$ & Standard error & $\mathbf{P}$ value \\
\hline Higher parental education & $0.68(0.46$ to 0.90$)$ & 0.11 & $<0.001$ \\
Both parents working (employed) & $0.31(-0.16$ to 0.77$)$ & 0.24 & 0.201 \\
Greater number of siblings & $-0.70(-1.11$ to -0.28$)$ & 0.21 & 0.001 \\
Greater number of persons in child's living room & $-0.40(-0.73$ to -0.06$)$ & 0.17 & 0.022 \\
Higher neighborhood income & $1.07(0.73$ to 1.40$)$ & 0.17 & $<0.001$ \\
\hline
\end{tabular}

${ }^{\mathrm{a}}$ The model is adjusted for age and gender.

${ }^{\mathrm{b}} \mathrm{R}^{2}$ for the model $=0.329$.

families having lower socioeconomic class do not afford these trends, and tend to be physically active and eat healthy food.

Efforts to stop childhood obesity should be made on all fronts and targeted interventions, designed considering the impact of family environment, should begin early in life [9]. Parents are important in terms of role-modeling physical activity, providing a safe and interesting backyard for children to play in, setting rules about how small screen entertainment is used in the home, guiding behavioral approaches to family food consumption and providing healthy food choices in home [51]. Counseling families on behavior change has been suggested as the best approach to prevent and manage childhood obesity [52]. Prevention and treatment effort following a global approach with proper monitoring and implementation are effective and there is little evidence of negative effects, either physiological or psychological [53-55]. Family-based interventions are routinely recommended for obese school-aged children and school-based programs are recommended for those at risk of being overweight and obese [55]. However, these interventions have been implemented in the developed countries and need to be tested in the resource-poor developing country settings. In Pakistan, public health infrastructure is available to support family- and schoolbased interventions regarding childhood obesity but these have not been implemented in the country. A National preventive strategy for childhood obesity should be developed and a pilot preventive program should be initiated taking into consideration the impact of family-based factors associated with childhood overweight and obesity. School health and nutrition supervisors working under Pakistan's National maternal, newborn, and child health Program could be involved for implementing school-based initiatives and lady health workers working under Pakistan's National program for family planning and primary health care could be involved for implementing familybased initiatives.

Cross-sectional nature of the study should be considered when interpreting the findings reported and future longitudinal studies are warranted to establish the temporal nature and causality of these associations. The effects of puberty on anthropometric indices were not explored in the present study; however, future studies are suggested in this regard. Although data collection followed a standard protocol, digital scales were not used. Variability in the data ascertainment may have introduced an error into the estimates; however, we do not anticipate large or systematic differences. These findings can be generalized to South Asian primary school children that share the same genetic and environmental factors with the sample.

\section{Conclusions}

Family-based factors were significantly associated with overweight and obesity among school-aged children in Pakistan. Children having higher parental education, both parents working, fewer siblings, less crowded housing and residence in high-income neighborhoods were significantly more likely to be overweight and obese. Higher parental education, living in high-income neighborhoods and fewer siblings were independent predictors of overweight. These findings support the need to design evidence-based child health policy and implement targeted interventions, considering the impact of family-based factors and involving communities.

\section{Acknowledgements}

We dedicate the work to loving memories of Ubeera Shahid (1987-2010, Allama lqbal Medical College Class of 2011) who left us in an unfortunate motorway car accident. We are grateful to Professor Arif M Siddiqui, MBBS, MRCP, FRCP (Eng), FRCP (Ed), FRCP (Glasg), Usman Khurshid, MBBS, Komal Mushtaq, Fourth year MBBS, Kiran Munawar, MBBS, Aqib Javed, Final Year MBBS, and others at the Ubeera Memorial Research Society of Allama Iqbal Medical College, Lahore, Pakistan. We would like to thank Dina Kakar, MD, Andrea Lyman, MD, MSC, MS and Douglas Proops MD, MPH. We are indebted to children, parents and staff at the sampled schools. We acknowledge partial financial support from Allama lqbal Medical College and technical support from the Punjab Departments of Health and Education, Lahore, Pakistan.

\section{Author details}

'Ubeera Memorial Research Society, Allama Iqbal Medical College, Lahore, 54000 Punjab, Pakistan. ${ }^{2}$ District Health Office Nankana Sahib, Punjab Department of Health, Nankana Sahib, 39100 Punjab, Pakistan.

\section{Authors' contributions}

MUM, principal investigator, conceived and implemented the study, analyzed and interpreted the data, prepared the manuscript and supervised the entire project. SG, MMS and HMA contributed to the study analysis, 
interpretation and manuscript preparation. US contributed to the study conception, implementation and analysis. MAS and AMS oversaw the study conception, implementation and manuscript preparation. All authors read and approved the final manuscript.

\section{Competing interests}

The authors declare that they have no competing interests.

Received: 15 June 2011 Accepted: 16 December 2011

Published: 16 December 2011

\section{References}

1. World Health Organization (WHO): Global Strategy on Diet, Physical Activity and Health Geneva, Switzerland: WHO; 2004

2. Dietz WH, Robinson TN: Overweight children and adolescents. N Engl J Med 2005, 352:2100-2109.

3. Han JC, Lawlor DA, Kimm SYS: Childhood obesity. Lancet 2010, 375:1737-1748.

4. Prentice AM: The emerging epidemic of obesity in developing countries. Int J Epidemiol 2006, 35:93-99.

5. Mushtaq MU, Gull S, Abdullah HM, Shahid U, Shad MA, Akram J: Prevalence and socioeconomic correlates of overweight and obesity among Pakistani primary school children. BMC Public Health 2011, 11(1):724.

6. Must A, Spadano J, Coakley EH, Field AE, Colditz G, Dietz WH: The disease burden associated with overweight and obesity. JAMA 1999, 282:1523-9.

7. Viner RM, Cole TJ: Adult socioeconomic, educational, social, and psychological outcomes of childhood obesity: a national birth cohort study. BMJ 2005, 330(7504):1354

8. World Health Organization (WHO): Obesity: Preventing and Managing the Global Epidemic Geneva, Switzerland: WHO; 2000

9. Reilly Jj: Tackling the obesity epidemic: new approaches. Arch Dis Child 2006, 91:724-6.

10. Kleiser C, Rosario AS, Mensink GBM, Prinz-Langenohl R, Kurth BM: Potential determinants of obesity among children and adolescents in Germany: results from the cross-sectional KiGGS study. BMC Public Health 2009, 9:46.

11. Salsberry PJ, Reagan PB: Dynamics of Early Childhood Overweight. Pediatrics 2005, 116(6):1329-1338.

12. Swinburn B, Gill T, Kumanyika S: Obesity prevention: a proposed framework for translating evidence into action. Obes Rev 2005, 6:23-33.

13. Baltrus PT, Lynch JW, Everson-Rose S, Raghunathan TE, Kaplan GA: Race/ Ethnicity, Life-Course Socioeconomic Position, and Body Weight Trajectories Over 34 years: The Alameda County Study. Am J Public Health 2005, 95(9):1595-1601.

14. Lamerz A, Kuepper-Nybelen J, Wehle C, et al: Social class, parental education, and obesity prevalence in a study of six-year-old children in Germany. Int J Obes (Lond) 2005, 29(4):373-80.

15. Danielzik S, Czerwinski-Mast M, Langnase K, Dilba B, Muller MJ: Parental overweight, socioeconomic status and high birth weight are the major determinants of overweight and obesity in 5-7 y-old children: baseline data of the Kiel Obesity Prevention Study (KOPS). Int J Obes Relat Metab Disord 2004, 28(11):1494-502.

16. Kocaoglu B, Moschonis G, Dimitriou M, et al: Parental educational level and cardiovascular disease risk factors in schoolchildren in large urban areas of Turkey: Directions for public health policy. BMC Public Health 2005, 5:13.

17. Huerta M, Bibi H, Haviv J, Scharf S, Gdalevich M: Parental smoking and education as determinants of overweight in Israeli children. Prev Chronic Dis 2006, 3(2):A48.

18. Brophy S, Cooksey R, Gravenor MB, et al: Risk factors for childhood obesity at age 5: Analysis of the Millennium Cohort Study. BMC Public Health 2009, 9:467.

19. Apfelbacher CJ, Loerbroks A, Cairns J, Behrendt H, Ring J, Krämer U: Predictors of overweight and obesity in five to seven-year-old children in Germany: Results from cross-sectional studies. BMC Public Health 2008, 8:171.

20. Hawkins SS, Cole TJ, Law C, the Millennium Cohort Study Child Health Group: An ecological systems approach to examining risk factors for early childhood overweight: findings from the UK Millennium Cohort Study. J Epidemiol Community Health 2009, 63:147-155.
21. Robinson WR, Gordon-Larsen P, Kaufman JS, Suchindran CM, Stevens J: The female-male disparity in obesity prevalence among black American young adults: contributions of sociodemographic characteristics of the childhood family. Am J Clin Nutr 2009, 89:1204-12.

22. Monteiro CA, Conde WL, Popkin BM: Independent effects of income and education on the risk of obesity in the Brazilian adult population. J Nutr 2001, 131:881S-886S

23. Kries R, Bolte G, Baghi L, Toschke AM, GME Study Group: Parental smoking and childhood obesity-is maternal smoking in pregnancy the critical exposure? Int J Epidemiol 2008, 37:210-216.

24. Hakeem R: Socio-economic differences in height and body mass index of children and adults living in urban areas of Karachi, Pakistan. Eur J Clin Nutr 2001, 55:400-406.

25. Sidhu S, Marwah G, Prabhjot : Prevalence of overweight and obesity among the affluent adolescent school children of Amritsar, Punjab. Coll Antropol 2005, 29:53-55.

26. Chhatwal J, Verma M, Riar SK: Obesity among pre-adolescent and adolescents of a developing country (India). Asia Pac J Clin Nutr 2004, 13:231-235.

27. Wang Y: Cross-national comparison of childhood obesity: the epidemic and the relationship between obesity and socioeconomic status. Int J Epidemiol 2001, 30:1129-1136.

28. Veugelers PJ, Fitzgerald AL: Prevalence of and risk factors for childhood overweight and obesity. CMAJ 2005, 173(6):607-613.

29. Melnick TA, Rhoades SJ, Wales KR, Cowell C, Wolfe WS: Overweight school children in New York City: prevalence estimates and characteristics. Int J Obes 1998, 22:7-13.

30. Van Lenthe FJ, Mackenbach JP: Neighbourhood deprivation and overweight: the GLOBE study. Int J Obes Relat Metab Disord 2002, 26:234-40.

31. Willms JD, Tremblay MS, Katzmarzyk PT: Geographic and demographic variation in the prevalence of overweight Canadian children. Obes Res 2003, 11:668-73.

32. INCLEN: Body mass index and cardiovascular disease risk factors in seven Asian and five Latin American centers data from the International Clinical Epidemiology Network (INCLEN). Obes Res 1996, 4:221-228.

33. Thorpe LE, List DG, Marx T, May L, Helgerson SD, Frieden TR: Childhood obesity in New York City elementary school students. Am J Public Health 2004, 94(9):1496-500

34. Kelishadi R, Ardalan G, Gheiratmand R, et al: Association of physical activity and dietary behaviours in relation to the body mass index in a national sample of Iranian children and adolescents: CASPIAN Study. Bull World Health Organ 2007, 85:19-26.

35. Whelton H, Harrington J, Crowley E, Kelleher V, Cronin M, Perry IJ: Prevalence of overweight and obesity on the island of Ireland: results from the North South Survey of Children's Height, Weight and Body Mass Index, 2002. BMC Public Health 2007, 7:187.

36. ZT Mechanical Physician Scale, East High Scales, China Scale Manufacturer, Nanjing, China. [http://www.easthighscale.com/ZTMechanical-Physician-Scale.html].

37. Sweeting $\mathrm{H}$ : Measurement and definitions of obesity in childhood and adolescence: a field guide for the uninitiated. Nutr J 2007, 6:32.

38. Durkin MS, Islam S, Hasan ZM, Zaman SS: Measures of socioeconomic status for child health research: comparative results from Bangladesh and Pakistan. Soc Sci Med 1994, 38:1289-1297.

39. Galobardes B, Shaw M, Lawlor DA, Lynch JW, Smith GD: Indicators of socioeconomic position (part 2). J Epidemiol Community Health 2006, 60(2):95-101.

40. World Health Organization: WHO Child Growth Standards [http://www.who. int/growthref/en/]

41. Butte NF, Garza C, de Onis M: Evaluation of the feasibility of international growth standards for school-aged children and adolescents. J Nutr 2007, 137:153-157.

42. Shrewsbury V, Wardle J: Socioeconomic Status and Adiposity in Childhood: A Systematic Review of Cross-sectional Studies 1990-2005. Obesity (Silver Spring) 2008, 16:275-284.

43. Ukwuani F, Suchindran C: Implications of women's work for child nutritional status in sub-Saharan Africa: A case study of Nigeria. Soc Sci Med 2003, 56(10):2109-2121.

44. Monteiro CA, Conde WL, Lu B, Popkin BM: Obesity and inequities in health in the developing world. Int J Obes 2004, 28:1181-1186. 
45. Wang Y, Beydoun MA: The Obesity Epidemic in the United StatesGender, Age, Socioeconomic, Racial/Ethnic, and Geographic Characteristics: A Systematic Review and Meta-Regression Analysis. Epidemiol Rev 2007, 29:6-28.

46. O'Dea JA: Gender, ethnicity, culture and social class influences on childhood obesity among Australian schoolchildren: implications for treatment, prevention and community education. Health Soc Care Community 2008, 16(3):282-290.

47. Miech RA, Kumanyika SK, Stettler N, Link BG, Phelan JC, Chang WW: Trends in the association of poverty with overweight among US adolescents, 1971-2004. JAMA 2006, 295:2385-2393.

48. Wang Y, Lobstein T: Worldwide trends in childhood overweight and obesity. Int J Pediatr Obes 2006, 1:11-25.

49. Chopra M, Galbraith S, Darnton-Hill I: A global response to a global problem: the epidemic of overnutrition. Bull World Health Organ 2002, 80:952-958.

50. Popkin BM: An overview on the nutrition transition and its health implications: the Bellagio meeting. Public Health Nutr 2002, 5:93-103.

51. Spurrier NJ, Margarey AA, Golley R, Curnow F, Sawyer MG: Relationships between the home environment and physical activity and dietary patterns of preschool children: a cross-sectional study. Int I Behav Nutr Phys Act 2008, 5:31.

52. Plourde G: Preventing and managing pediatric obesity. Can Fam Physician 2006, 52(3):322-328.

53. American Dietetic Association, Ritchie LD, Crawford PB, Hoelscher D, Sothern MS: Position of the American Dietetic Association: individual-, family-, school-, and community-based interventions for pediatric overweight. J Am Diet Assoc 2006, 106:925-945.

54. Epstein LH, Myers MD, Raynor H, Saelens BE: Treatment of pediatric obesity. Pediatrics 1998, 101(3):554-570.

55. Summerbell CD, Waters E, Edmunds LD, Kelly S, Brown T, Campbell KJ: Interventions for preventing obesity in children. Cochrane Database of Systematic Reviews 2005(3):CD001871.

\section{Pre-publication history}

The pre-publication history for this paper can be accessed here: http://www.biomedcentral.com/1471-2431/11/114/prepub

doi:10.1186/1471-2431-11-114

Cite this article as: Mushtaq et al:: Family-based factors associated with overweight and obesity among Pakistani primary school children. BMC Pediatrics 2011 11:114.

\section{Submit your next manuscript to BioMed Central and take full advantage of:}

- Convenient online submission

- Thorough peer review

- No space constraints or color figure charges

- Immediate publication on acceptance

- Inclusion in PubMed, CAS, Scopus and Google Scholar

- Research which is freely available for redistribution

Submit your manuscript at www.biomedcentral.com/submit
Biomed Central 